\title{
Hemodynamic Responses to Exercise in Clinically Normal Middle-aged Men and in Those with Angina Pectoris *
}

\author{
Glenn L. Foster † and T. Joseph Reeves with statistical analyses by \\ James H. Meade, JR. \\ (From the Department of Medicine, Medical College of Alabama, Birmingham, Ala.)
}

The effects of aging on the hemodynamic responses to exercise in men are at present poorly understood. Although a number of studies investigating these responses in young people have been reported, relatively few have been carried out in subjects older than 35 years. Granath, Jonsson, and Strandell (2) have described the results of exercise upon cardiac output and vascular pressures in a group of elderly normal men. More recently Levine and his associates (3) and Weissler, Peeler, and Roehll (4) have published data on normal subjects (as well as those with heart disease) that have included several in the middle years of life.

Several studies have been reported on the hemodynamic effects of exercise in subjects with coronary artery disease, but some of these were done on patients with advanced disease. Lewis, Houssay, Haynes, and Dexter (5) reported studies in three patients, all of whom had symptoms of severe congestive failure at the time of the study. Müller and Rørvik (6) had four patients with angina pectoris whose cardiac output and oxygen consumption were measured during exercise. Even at rather low levels of exercise these individuals developed chest pain and had an elevation of pulmonary wedge pressure coincident with the pain. Recently Messer, Levine, Wagman, and Gorlin (7) reported studies in 19 subjects with clinical coronary artery disease and found

\footnotetext{
* Submitted for publication April 16, 1962; accepted May 15, 1964.

Supported by the U. S. Public Health Service (HE 05080-04 and HE 03684), Mr. K. W. Berry, and the Edward E. and Mary Bishop Foundation.

Presented in part to the American Heart Association's Annual Meeting, 1961 (1).

+ Work performed during the tenure of a postdoctoral fellowship from the National Heart Institute, U. S. Public Health Service.
}

that there was a decreased rate of ejection during systole and a failure to increase "mechanical efficiency" during exercise when compared with normal controls.

Since the effect of arteriosclerotic heart disease has at times been thought to be qualitatively similar to aging, the abjectives of this study were 1) to determine certain hemodynamic responses to exercise in a group of normal subjects during the middle years of life and 2) to compare these findings with the response to exercise of a group of young normal subjects and to patients with angina pectoris.

\section{Methods}

Subjects. Two groups of normal subjects were compared with the angina patients. The first group of normal subjects (young normals) was composed of four white and three Negro males ranging in age from 16 to 35 years. The average age was 25.6 years. These individuals were laboratory personnel who had not been on any regular athletic program. Physical examination, chest $\mathrm{X}$ ray, and routine laboratory studies showed these subjects to be normal. The middle-aged group of normals consisted of six white and three Negro males whose ages ranged from 43 to 51 years and averaged 47.4 years. Four of these individuals were senior officers in the Birmingham Fire Department, one was a salesman, two were farmers, and two unemployed. Two of this group participated regularly in athletic activities, two had been hospitalized several days for unrelated problems (psoriasis and a pulmonary coin lesion), and the remaining five had continued their mostly sedentary activities. Cardiovascular examination, chest $\mathrm{X}$ rays, laboratory studies, and electrocardiographic findings on these individuals showed no cardiovascular abnormalities. The group of normal subjects is summarized in Table $\mathrm{I}$.

The angina pectoris patients were also divided into two groups. Table II summarizes their clinical findings. Their average age was 48.7 years. The first group of one Negro and six white males had no history of a previous myocardial infarction and were not taking digitalis. The other angina group also consisted of one 
TABLE I

Summary of the older and younger normal subjects

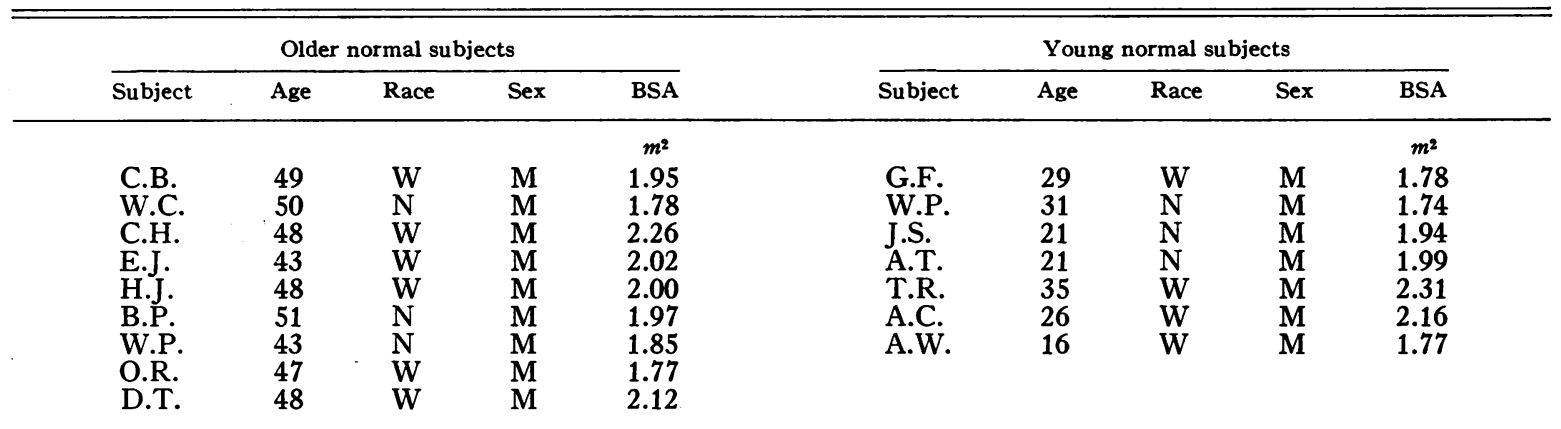

Average age, 47.4

Average age, 25.6

Negro and six white males. Five of these had had a previous myocardial infarction, and two of these five were taking digitalis at the time of the study. One of these (B.B.) had had symptoms suggestive of congestive failure in the past and had been digitalized by his private physician. The other (A.J.) had never been in congestive failure but was digitalized by his private physician in an attempt to ameliorate the course of the angina pectoris. The two patients in this group who had not had infarctions (R.H., E.M.) both had symptoms

TABLE II

Clinical summary of the patients with angina pectoris

\begin{tabular}{ccccc}
\hline & Age & & & \\
Pace \\
Patient & Sex & BSA & History & Resting ECG \\
\hline
\end{tabular}

A. Angina pectoris patients without previous infarction

\begin{tabular}{|c|c|c|c|c|c|}
\hline W.A. & $56 \mathrm{NM}$ & 2.02 & Angina for 3 years & Right bundle branch block & Normal \\
\hline W.B. & $43 \mathrm{WM}$ & 1.94 & Angina for 1 year & Nonspecific ST-T changes & Normal \\
\hline J.H. & $55 \mathrm{WM}$ & 1.88 & $\begin{array}{l}\text { Minimal angina, musculoskeletal } \\
\text { pains }\end{array}$ & Normal & $\begin{array}{c}\text { Diffuse bullous } \\
\text { emphysema }\end{array}$ \\
\hline R.M. & $46 \mathrm{WM}$ & 1.69 & Angina for 2 to 3 years & Normal & Normal \\
\hline E.R. & $40 \mathrm{WM}$ & 1.95 & $\begin{array}{l}\text { Angina for } 1 \text { year, musculoskeletal } \\
\text { pains for } 4 \text { years }\end{array}$ & Normal & Normal \\
\hline H.T. & $52 \mathrm{WM}$ & 1.94 & $\begin{array}{l}\text { Angina for } 8 \text { to } 10 \text { years, diabetes } \\
25 \text { years }\end{array}$ & Nonspecific ST-T changes & $\begin{array}{l}\text { Some changes of } \\
\text { pneumoconiosis }\end{array}$ \\
\hline J.W. & $42 \mathrm{WM}$ & 1.58 & $\begin{array}{l}\text { Angina for } 3 \text { years, diabetes } 22 \\
\text { years }\end{array}$ & Normal & Normal \\
\hline
\end{tabular}

B. Angina pectoris patients with previous infarction and/or taking digitalis

\begin{tabular}{|c|c|c|c|c|c|}
\hline L.A. & $53 \mathrm{WM}$ & 2.00 & $\begin{array}{l}\text { Angina for } 4 \text { years, infarct } 9 \text { years } \\
\text { ago }\end{array}$ & Essentially normal & $\begin{array}{l}\text { Within normal } \\
\text { limits }\end{array}$ \\
\hline B.B. & $42 \mathrm{WM}$ & 2.08 & Angina for 3 years, on digitalis & Old diaphragmatic infarct & Essentially normal \\
\hline R.H. & $53 \mathrm{NM}$ & 1.88 & $\begin{array}{l}\text { Angina } 3 \text { years, congestive heart } \\
\text { failure } 4 \text { years, compensated } \\
\text { with digitalis }\end{array}$ & Nonspecific ST-T changes & Essentially normal \\
\hline A.J. & $51 \mathrm{WM}$ & 1.64 & $\begin{array}{l}\text { Angina for } 3 \text { years, } 3 \text { previous in- } \\
\text { farcts }\end{array}$ & Old diaphragmatic infarct & Essentially normal \\
\hline E.M. & $51 \mathrm{WM}$ & 1.87 & $\begin{array}{l}\text { Angina for } 9 \text { years, congestive } \\
\text { heart failure } 2 \text { years, on digitalis }\end{array}$ & $\begin{array}{l}\text { Interventricular conduc- } \\
\text { tion defect }\end{array}$ & Essentially normal \\
\hline W.Pa. & $55 \mathrm{WM}$ & 1.76 & $\begin{array}{l}\text { Angina for } 7 \text { years, infarct } 6 \text { years } \\
\text { ago }\end{array}$ & Old posterior infarct & Not available \\
\hline J.R. & $43 \mathrm{WM}$ & 2.00 & $\begin{array}{l}\text { Angina for } 2 \text { years, infarct } 2 \text { years } \\
\text { ago }\end{array}$ & Old diaphragmatic infarct & Normal \\
\hline
\end{tabular}


suggesting congestive failure and were digitalized with improvement in their clinical course at that time. All of the patients were well compensated at the time of the study, and none showed cardiomegaly by chest $\mathrm{X}$ ray. The diagnosis of angina pectoris was made by finding a typical history of reproducible chest pain with exertion, relieved by rest or nitroglycerin or both. Most of these subjects also had electrocardiographic changes on exercise consistent with the diagnosis.

Before the hemodynamic study, all of the subjects were exercised in the supine position with the bicycle ergometer to determine a level of work they could maintain for several minutes without excessive dyspnea, fatigue, or chest pain. This procedure served to familiarize the patients with the laboratory and with the type of exercise employed. This individually determined level of exercise was used in the present study.

Technique. On the day of the study the subjects came to the laboratory in a fasting state without premedication and rested on a table for about 30 minutes before any procedures were started.

Under local anesthesia the right brachial artery was punctured with a no. 18 Cournand needle. A moderately stiff wire stylet was inserted through the needle into the lumen of the artery, the needle then withdrawn, and an outer cannula of a PE-160 Seldinger needle inserted over the wire stylet into the artery. This procedure was adopted to facilitate passage of the larger cannula into the artery with minimal trauma. After the wire stylet had been withdrawn, a flexible wire guide was passed through the cannula into the artery and the cannula then withdrawn. The flexible wire guide was then passed under fluoroscopic control into the ascending aorta and positioned above the aortic valve. A previously measured length of Teflon tubing (o.d., 0.059 ; i.d., $0.038)^{1}$ was filled with heparinized saline and passed over the wire guide so that the tip lay 1 or $2 \mathrm{~cm}$ above the aortic valve. With this technique, no subject experienced other than minimal transient discomfort, and no case of arterial damage was encountered. The guide was withdrawn and the tubing attached through a mechanical damping device to a Statham P23G strain gauge pressure transducer. The output of this gauge was recorded photographically on a multichannel oscillographic recorder ${ }^{2}$ at a paper speed of $100 \mathrm{~mm}$ per second. The frequency response of the optimally damped catheter manometer ${ }^{3}$ recorder system was found to be flat to $12 \mathrm{cps}$ with $50 \%$ transmission at $20 \mathrm{cps}$ without resonance amplification in this range.

A bipolar thoracic electrocardiogram was monitored throughout the procedure for heart rate. From the central aortic pressure tracings, the cycle length and ejection times were determined by averaging the individual values of four to eight consecutive cardiac cycles.

1 TTE 19, American Super-Temp Wires, Winooski, Vt. 2 Electronics for Medicine, White Plains, N. Y.

3 A damping device was made by using a screw clamp to compress a $5-\mathrm{cm}$ segment of Tygon tubing inserted between the catheter and the strain gauge.
The mean ejection and mean cycle pressures were obtained by planimetering four to eight consecutive cardiac cycles.

An accessible vein in the right antecubital fossa was also locally anesthetized and a no. 18 thin-walled needle inserted into the vein, through which a flexible wire guide was passed several centimeters. A $20-\mathrm{cm}$ length of Teflon tubing was passed over the guide, which was then removed. This tubing was fitted with a three-way stopcock and served as the route of dye injection.

Cardiac output determinations were made by the dye dilution technique. Five $\mathrm{mg}$ of indocyanine green ${ }^{4}$ diluted to $1 \mathrm{ml}$ in a preset spring-loaded syringe was rapidly injected into the venous circulation through one arm of the stopcock attached to the venous tubing. The tubing was immediately flushed with $10 \mathrm{ml}$ of saline by a syringe attached to the other arm of the stopcock. This method of dye injection has been shown to give results comparable to injecting the dye at the junction of the superior vena cava and right atrium (8). Arterial blood was drawn at a constant rate of $20 \mathrm{ml}$ per minute from the aortic catheter through a linear densitometer ${ }^{5}$ by a motor driven syringe. ${ }^{6}$ The densitometer was attached to the arterial catheter by a stopcock bypassing the damping device and the strain gauge. The aortic catheter, averaging $70 \mathrm{~cm}$ in length, had a volume of $0.55 \mathrm{ml}$. The associated connectors and tubing to the cuvette brought the total volume in the sampling system from the central aorta to the cuvette to approximately $1.5 \mathrm{ml}$. The output from the densitometer was amplified and recorded at $5 \mathrm{~mm}$ per second paper speed. The area of the dye curve was obtained by the semilogarithmic replot technique and the trapezoid method of integration at 1 -second intervals. The heart rate, as obtained from the ECG recorded during the cardiac output determination, was used to calculate the stroke volume. The Hamilton equation (9) for calculating cardiac output was then used. In three of the young normal subjects the cardiac output determinations were by the direct Fick method, using pulmonary artery and aortic blood samples.

Oxygen consumption was measured by collecting the expired air into a Douglas bag for 3 minutes at rest and for 1 minute during exercise. Expired gas volumes were measured with a wet test gasometer and the oxygen and carbon dioxide contents determined by the Scholander method. All gas analyses were completed within 2 hours of collection.

Procedure. The catheters were inserted with little discomfort into the subjects, and no particular change in resting heart rate or respiration was noticed. Two cardiac output determinations were made at rest within a period of 10 minutes, with pressure recordings immediately before and after each of the output determinations. The duplicate measurements were found to agree within 9.3\% with a standard error of $0.285 \mathrm{~L}$ per minute per

4 Hynson, Westcott and Dunning, Baltimore, Md.

5 Model XP-250A, Waters Co., Rochester, Minn.

6 Harvard Apparatus Co., model 900-S, Dover, Mass. 
$\mathrm{m}^{2}$. We appreciate that part of the variation is a result of changing physiologic state and a part the result of error of measurement. Pulmonary ventilation and oxygen consumptions were measured during the second output determinations.

All of the subjects then exercised in the supine position on a constant speed variable load bicycle ergometer previously described by Donald, Bishop, Cumming, and Wade (10). The normal subjects (with two exceptions) completed three different levels of exercise of 4 minutes each. At the conclusion of one 4-minute period of exercise, the load on the bicycle ergometer was immediately increased to the next level and the exercise continued without interruption. Pressure recordings were obtained every 30 seconds during exercise. During the fourth minute of each level of exercise the cardiac output was determined and expired gas for measurement of pulmonary ventilation and oxygen consumption obtained.

The patients with angina pectoris followed an identical program except that most performed only one level of exercise. Two subjects were able to complete two levels of exercise. Another terminated the period of exercise at 2 minutes because chest pain appeared. Cardiac output and ventilation were determined during the last minute of this subject's exercise. No other subject experienced anginal pain during the procedure.

\section{Results}

The results are presented in Table III. Even though the normal subjects and two of the angina patients were able to perform more than one level of exercise, only the first level is presented here, because the statistical analysis was based on these values.

Rest. Seven variables at rest were compared in the normal group and in those with angina pec-

TABLE III

Hemodynamic variables at rest and during exercise in normal subjects

\begin{tabular}{|c|c|c|c|c|c|c|c|c|c|c|}
\hline \multirow[b]{2}{*}{ Subject } & \multicolumn{2}{|c|}{$\mathrm{O}_{2}$ uptake } & \multicolumn{2}{|c|}{ Cardiac index } & \multicolumn{2}{|c|}{ Heart rate } & \multicolumn{2}{|c|}{$\begin{array}{c}\text { Aortic pressure } \\
\text { (systolic/diastolic) }\end{array}$} & \multicolumn{2}{|c|}{ Ejection time } \\
\hline & Rest & Exercise & Rest & Exercise & Rest & Exercise & Rest & Exercise & Rest & Exercise \\
\hline A. Yo & \multicolumn{2}{|c|}{$\begin{array}{c}\mathrm{ml} / \mathrm{min} / \mathrm{m}^{2} \\
\mathrm{mal} \text { subjects }\end{array}$} & & & & & \multicolumn{2}{|l|}{ r } & \multicolumn{2}{|c|}{ sec } \\
\hline $\begin{array}{l}\text { G.F. } \\
\text { W.P. } \\
\text { J.S. } \\
\text { A.T. } \\
\text { T.R. } \\
\text { A.C. } \\
\text { A.W. }\end{array}$ & $\begin{array}{l}127 \\
166 \\
134 \\
121 \\
128 \\
154 \\
173\end{array}$ & $\begin{array}{l}492 \\
513 \\
354 \\
446 \\
343 \\
340 \\
346\end{array}$ & $\begin{array}{l}2.51 \\
3.19 \\
3.07 \\
3.18 \\
3.45 \\
3.69 \\
3.91\end{array}$ & $\begin{array}{l}5.10 \\
5.68 \\
4.85 \\
5.63 \\
5.63 \\
4.65 \\
5.78\end{array}$ & $\begin{array}{l}52 \\
78 \\
63 \\
72 \\
73 \\
74 \\
85\end{array}$ & $\begin{array}{r}102 \\
118 \\
88 \\
101 \\
88 \\
96 \\
115\end{array}$ & $\begin{array}{l}113 / 73 \\
117 / 80 \\
102 / 77 \\
134 / 84 \\
108 / 76 \\
158 / 79 \\
120 / 78\end{array}$ & $\begin{array}{l}132 / 84 \\
149 / 94 \\
124 / 92 \\
144 / 93 \\
114 / 76 \\
173 / 93 \\
132 / 93\end{array}$ & $\begin{array}{l}0.324 \\
0.288 \\
0.310 \\
0.268 \\
0.325 \\
0.296 \\
0.270\end{array}$ & $\begin{array}{l}0.295 \\
0.265 \\
0.288 \\
0.247 \\
0.300 \\
0.294 \\
0.250\end{array}$ \\
\hline \multicolumn{11}{|c|}{ B. Older normal subjects } \\
\hline $\begin{array}{l}\text { C.B. } \\
\text { W.C. } \\
\text { C.H. } \\
\text { E.J. } \\
\text { H.J. } \\
\text { B.P. } \\
\text { W.P. } \\
\text { O.R. } \\
\text { D.T. }\end{array}$ & $\begin{array}{r}99 \\
129 \\
152 \\
164 \\
146 \\
145 \\
156 \\
174 \\
143\end{array}$ & $\begin{array}{l}421 \\
501 \\
432 \\
471 \\
359 \\
411 \\
387 \\
597 \\
388\end{array}$ & $\begin{array}{l}2.38 \\
2.29 \\
2.90 \\
2.78 \\
3.04 \\
2.55 \\
3.61 \\
3.26 \\
2.65\end{array}$ & $\begin{array}{l}4.96 \\
4.45 \\
5.39 \\
5.20 \\
5.90 \\
4.27 \\
5.89 \\
6.83 \\
4.07\end{array}$ & $\begin{array}{l}61 \\
53 \\
71 \\
52 \\
65 \\
92 \\
67 \\
71 \\
74\end{array}$ & $\begin{array}{r}95 \\
75 \\
105 \\
75 \\
103 \\
114 \\
98 \\
110 \\
98\end{array}$ & $\begin{array}{r}109 / 63 \\
88 / 59 \\
138 / 89 \\
91 / 60 \\
96 / 51 \\
114 / 79 \\
148 / 87 \\
110 / 66 \\
114 / 67\end{array}$ & $\begin{array}{l}135 / 74 \\
138 / 81 \\
177 / 109 \\
115 / 69 \\
116 / 95 \\
158 / 90 \\
152 / 94 \\
142 / 74 \\
149 / 78\end{array}$ & $\begin{array}{l}0.310 \\
0.292 \\
0.290 \\
0.318 \\
0.300 \\
0.247 \\
0.300 \\
0.295 \\
0.315\end{array}$ & $\begin{array}{l}0.295 \\
0.305 \\
0.280 \\
0.325 \\
0.288 \\
0.258 \\
0.253 \\
0.240 \\
0.308\end{array}$ \\
\hline
\end{tabular}

C. Angina pectoris patients without previous myocardial infarction

\begin{tabular}{|c|c|c|c|c|c|c|c|c|c|c|}
\hline $\begin{array}{l}\text { W.A. } \\
\text { W.B. } \\
\text { J.H. } \\
\text { R.M. } \\
\text { E.R. } \\
\text { H.T. } \\
\text { J.W. }\end{array}$ & $\begin{array}{l}148 \\
152 \\
180 \\
143 \\
122 \\
131 \\
125\end{array}$ & $\begin{array}{l}613 \\
245 \\
469 \\
516 \\
515 \\
330 \\
310\end{array}$ & $\begin{array}{l}3.22 \\
3.33 \\
2.96 \\
2.83 \\
2.59 \\
2.23 \\
2.76\end{array}$ & $\begin{array}{l}4.86 \\
3.03 \\
4.01 \\
4.95 \\
4.43 \\
3.11 \\
3.76\end{array}$ & $\begin{array}{l}87 \\
75 \\
67 \\
78 \\
66 \\
65 \\
67\end{array}$ & $\begin{array}{r}115 \\
102 \\
94 \\
115 \\
123 \\
80 \\
83\end{array}$ & $\begin{array}{l}151 / 67 \\
141 / 84 \\
116 / 72 \\
128 / 84 \\
123 / 72 \\
151 / 78 \\
107 / 64\end{array}$ & $\begin{array}{l}187 / 77 \\
150 / 98 \\
138 / 80 \\
161 / 95 \\
149 / 80 \\
182 / 90 \\
150 / 81\end{array}$ & $\begin{array}{l}0.260 \\
0.317 \\
0.284 \\
0.280 \\
0.320 \\
0.253 \\
0.280\end{array}$ & $\begin{array}{l}0.240 \\
0.280 \\
0.273 \\
0.260 \\
0.258 \\
0.275 \\
0.285\end{array}$ \\
\hline
\end{tabular}

D. Angina pectoris patients with previous myocardial infarction and/or on digitalis

\begin{tabular}{|c|c|c|c|c|c|c|c|c|c|c|}
\hline $\begin{array}{l}\text { L.A. } \\
\text { B.B. } \\
\text { R.H. } \\
\text { A.J. } \\
\text { E.M. } \\
\text { W.Pa. } \\
\text { J.R. }\end{array}$ & $\begin{array}{l}155 \\
163 \\
148 \\
165 \\
143 \\
118 \\
126\end{array}$ & $\begin{array}{l}344 \\
286 \\
447 \\
422 \\
395 \\
227 \\
419\end{array}$ & $\begin{array}{l}3.66 \\
2.74 \\
2.61 \\
2.71 \\
4.28 \\
1.89 \\
2.52\end{array}$ & $\begin{array}{l}4.33 \\
3.94 \\
4.18 \\
3.94 \\
5.18 \\
2.11 \\
4.43\end{array}$ & $\begin{array}{l}62 \\
61 \\
90 \\
68 \\
80 \\
66 \\
62\end{array}$ & $\begin{array}{r}102 \\
80 \\
120 \\
96 \\
111 \\
115 \\
86\end{array}$ & $\begin{array}{r}100 / 58 \\
163 / 86 \\
151 / 90 \\
145 / 72 \\
98 / 55 \\
130 / 66 \\
112 / 72\end{array}$ & $\begin{array}{l}133 / 78 \\
169 / 93 \\
184 / 107 \\
163 / 80 \\
139 / 76 \\
153 / 88 \\
135 / 83\end{array}$ & $\begin{array}{l}0.290 \\
0.293 \\
0.280 \\
0.288 \\
0.252 \\
0.300 \\
0.305\end{array}$ & $\begin{array}{l}0.285 \\
0.287 \\
0.270 \\
0.277 \\
0.255 \\
0.253 \\
0.282\end{array}$ \\
\hline
\end{tabular}


TABLE IV

Comparison of mean values at first level of exercise: values on older normal subjects and pooled patients with angina pectoris

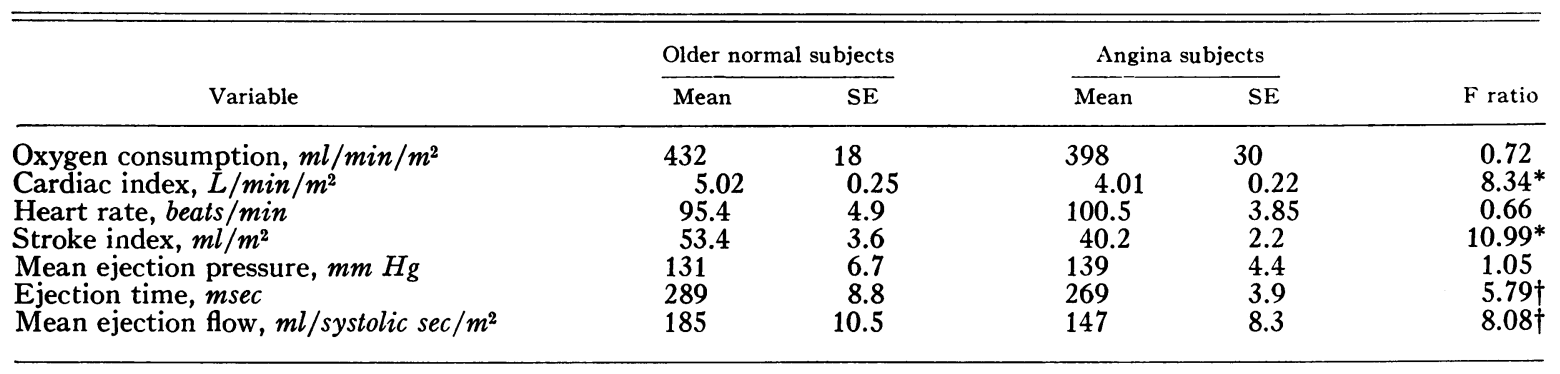

* Significant at the 0.01 level.

$\dagger$ Significant at the 0.05 level.

toris. These variables were: 1 ) oxygen consumption (corrected to body surface area) ; 2) cardiac index; 3) heart rate; 4) stroke index; 5) mean ejection pressure; 6) ejection time (systolic ejection period); and 7) mean ejection flow (mean systolic ejection rate), which is stroke index divided by ejection time.

The two groups of angina pectoris patients (those without previous infarction versus those with previous infarction or on digitalis or both) were compared by an analysis of variance (11). In all analyses significance was tested at the 0.05 level. There was no significant difference at rest in any of the seven variables. Since there was no significant difference between these two angina groups, they were pooled and then compared with the older normal subjects. An analysis of variance again showed no significant difference between the pooled angina group and the normal subjects at rest.

There was also no significant difference at rest between the young normal subjects and the middleaged normal subjects in any of the variables.

TABLE V

F ratios* obtained from an analysis of variance (on slopes) for the older normal subjects versus the pooled angina pectoris patients

1. Cardiac index/oxygen consumption

2. Heart rate/oxygen consumption

3. Stroke index/oxygen consumption

4. Mean ejection pressure/oxygen consumption

5. Mean ejection flow/heart rate

6. Ejection time/heart rate

* The $\mathrm{F}$ ratio is a method of testing the significance of differences between groups (11). With 20 observations, an $F$ ratio of 4.38 is needed for significance at the 0.05 level, and a ratio of 8.18 is needed at the 0.01 level.
Exercise. The comparison of mean values at the first level of exercise between the older normal subjects and the pooled patients with angina pectoris is shown in Table IV. It is seen that at very similar oxygen consumptions, the cardiac index, stroke volume, and mean ejection flow values were significantly greater in the normal subjects than in patients with angina pectoris. The duration of ejection systole was significantly longer in the normal subjects.

A more precise and meaningful comparison, however, would be a comparison of the slopes or degree of change from rest to exercise in the different groups. The slopes were calculated by the equation, $B=\left(Y_{1}-Y_{0}\right) /\left(X_{1}-X_{0}\right)$, where $B$ is the slope, $X_{1}$ the independent variable at the first level of exercise, $Y_{1}$ the dependent variable at the first level of exercise, $X_{0}$ the independent variable at rest, and $Y_{0}$ the dependent variable at rest.

The slopes that were calculated for each individual were 1) cardiac index/oxygen consumption (all oxygen consumption values are corrected to body surface area); 2) heart rate/oxygen consumption; 3) stroke index/oxygen consumption; 4) mean ejection pressure/oxygen consumption; 5) mean ejection flow/heart rate; and 6) ejection time/heart rate.

An analysis of variance on the slopes of the two different groups of angina patients showed no significant difference for any of the six variables. The two angina groups were then pooled and compared with the older normal group. Table $\mathrm{V}$ shows the $\mathrm{F}$ ratios on slopes where the older normals were compared to the angina groups. Comparison between the angina and older control 
group shows not only an absolute difference in the cardiac index and stroke index for a given level of oxygen consumption, but the degree of change (or slope) was significantly different for the cardiac index and very nearly significant (at the 0.05 level) for the stroke index. The slope of the mean ejection flow/heart rate was also significant. The results can be best visualized, however, when they are displayed as shown in Figures 1 to 3 .

Cardiac index. Figure 1 shows the relationship between the cardiac index and oxygen consumption. The left-hand panels show the younger and older normal subjects, and the right-hand panels, the angina patients. The shaded area represents the $95 \%$ confidence limits established by Donald and colleagues (10) for young normal subjects.

It can be seen that the cardiac outputs of the normal subjects are higher than the angina pa- tients at the same level of oxygen consumption. The slope of the lines connecting the resting and first level of exercise is also significantly higher in the control group than in the angina patients. (The regression equation for the older normal controls is $Y=2.61+0.0061 X$, where $Y$ is cardiac output in liters per minute per meter squared and $X$ is the oxygen consumption in milliliters per minute per meter squared. For the angina group, $Y=2.25+0.0045 X$.) The average of nine elderly men (mean age, 70.7) in Granath's study (2) is shown by an $\mathrm{X}$ in the same figure as the normals over 40 . One of the young normal subjects and two of the older normal group had points that fell below the values representing the 95\% confidence limits in Donald's study. The one subject in the angina group whose cardiac output fell with exercise was the one who experienced an attack of anginal pain during exercise.

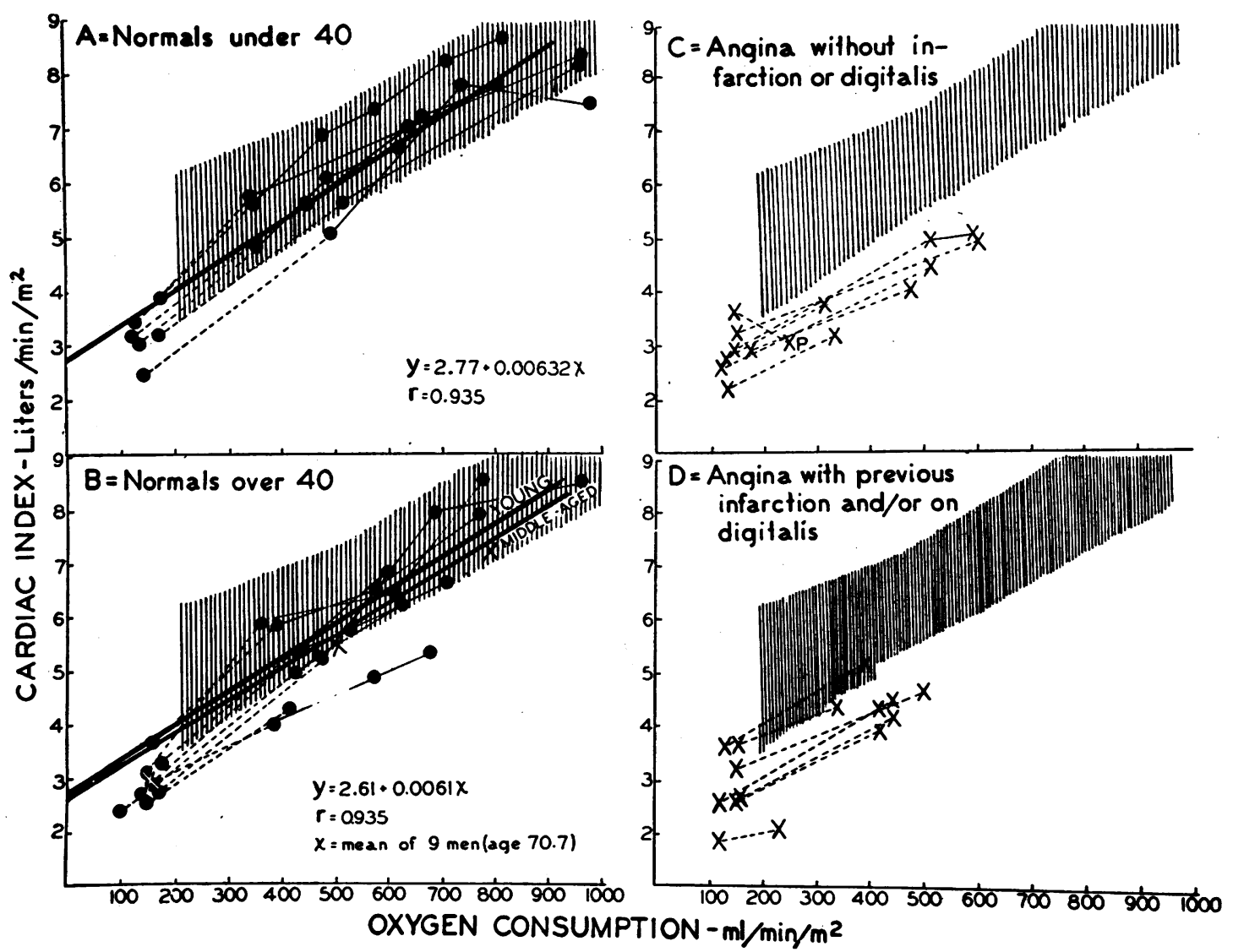

Fig. 1. Cardiac index as a function of OXYGen consumption for Normal subjects (A AND B) AND ANGINA PECTORIS PATIENTS (C AND D). The shaded area represents the $95 \%$ confidence limits established by Donald and co-workers (10) for young normal subjects. The heavy lines in panels A and B are the mean regression lines for the group. 


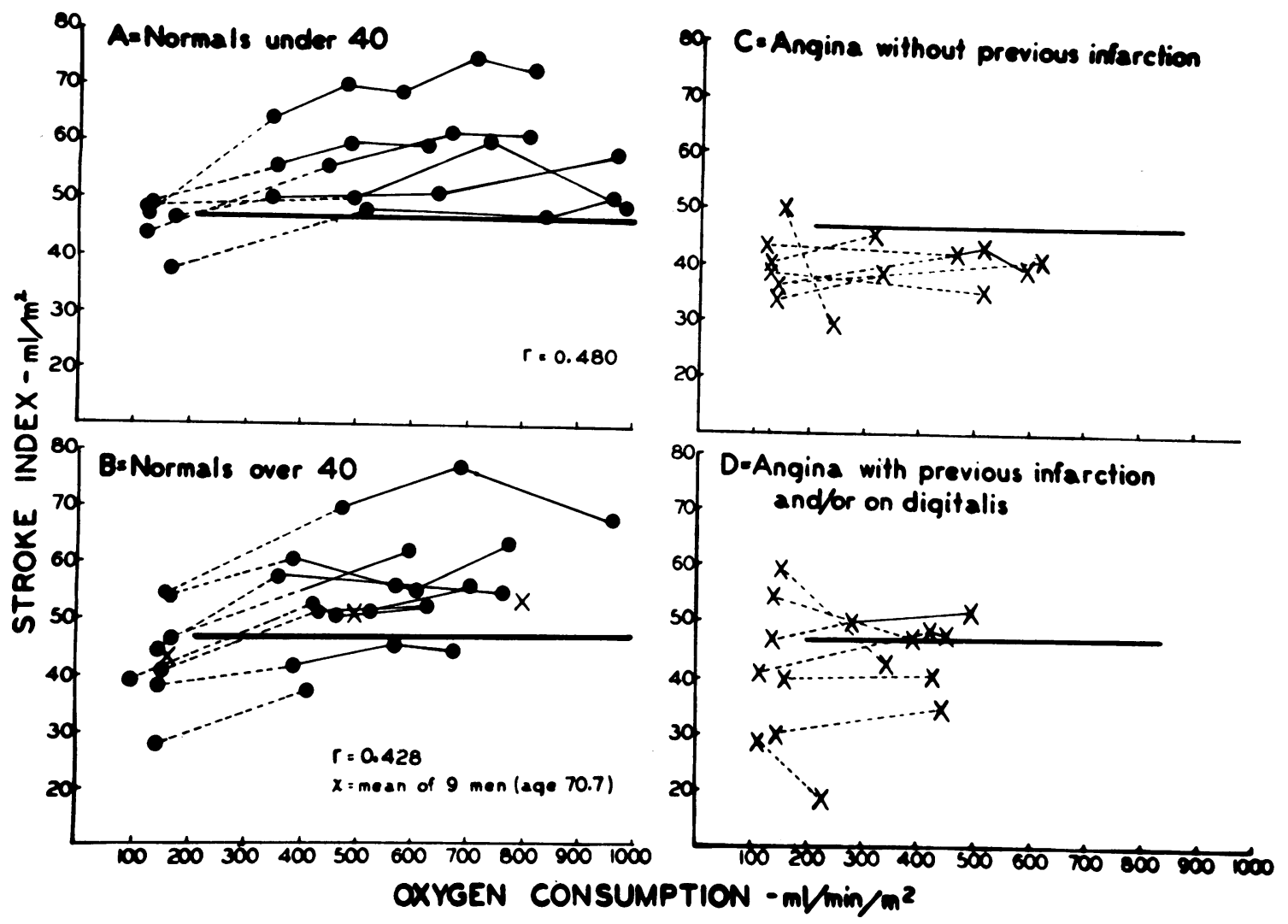

Fig. 2. Stroke index as a function of oxygen consumption for NoRmal subjects (A ANd B) ANd ANGina PECTORIS Patients (C AND D). The heavy line at $47 \mathrm{ml}$ per $\mathrm{m}^{2}$ is the minimal exercise value for young normal subjects.

Heart rate. Although the differences in heart rate were not statistically significant in the different groups, there was an apparent tendency of the heart rate to rise more rapidly in the anginal subjects at increasing levels of oxygen consumption than in the normal groups.

Stroke index. The reduced cardiac output at essentially similar heart rates seen in the patients with angina is a reflection of the differences in stroke volume between these subjects and the normal groups. This is shown in Figure 2. During exercise, the stroke indexes of all the young normal subjects and all but two of the middle-aged normal individuals were greater than $47 \mathrm{ml}$ per $\mathrm{m}^{2}$, whereas all but three of the group with angina pectoris fell below this value. This difference was highly significant $(p<0.01)$. No differences were noticeable at rest.

Ejection time. When the duration of systolic ejection, as measured in the ascending aorta, is plotted against heart rate, there is a reduction in ejection time with increasing heart rate that is similar in all the groups. No significant differences were noted among any of the groups.

Mean ejection pressure. The average pressure in the aorta during ejection rose linearly with increasing levels of exercise. The degree of rise for a given level of oxygen consumption was slightly greater in the older group of normal subjects than in the younger group. There was a tendency for the angina patients to have a slightly higher mean ejection pressure than the normal controls. The younger normal subjects had an expected lower ejection pressure than did the older normal subjects. None of these differences, however, was significant.

Mean ejection flow. When the stroke index is divided by the duration of ejection, a figure representing the average flow of blood ejected from the left ventricle is obtained. This value has also been termed "mean systolic ejection rate" $(3,7)$. In both normal groups there was an approximately 
equal increase in this mean ejection flow with increasing heart rate. The angina patients, by contrast, failed to show this rise of mean ejection flow. There was no significant difference between the two normal groups. There was likewise no significant difference between the two groups of angina pectoris patients. The relationship among these groups is shown in Figure 3 . The regression equation of the pooled angina pectoris values was $Y=131-0.11 X$, where $X$ is the heart rate in beats per minute. There was a significant difference between the older normal subjects and the pooled patients with coronary artery disease during exercise.

\section{Discussion}

Hemodynamic consequences of aging. Relatively few studies have been published that allow an examination of the hemodynamic response to exercise as a function of aging. Only 3 of Donald's 16 normal subjects (10) and 1 of 10 of the

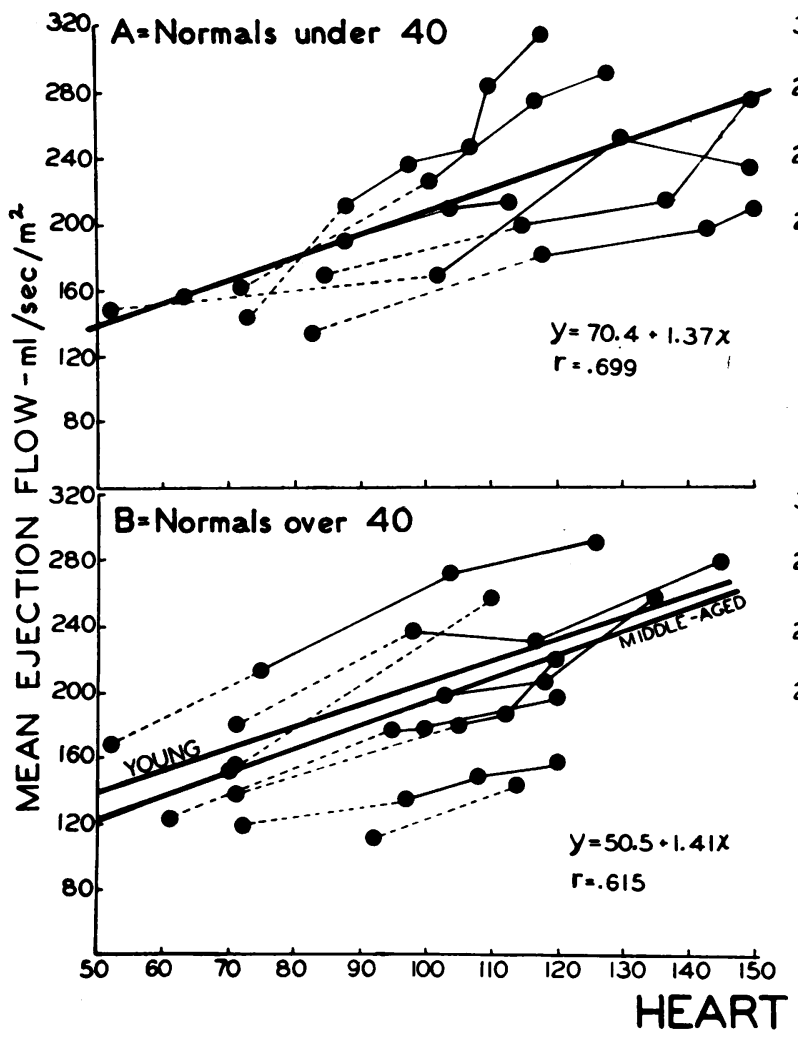

normals in Holmgren, Jonsson, and Sjöstrand's study (12) were in the age group of our older subjects. In neither of these studies could a difference in the response of the older subjects be detected. Granath and associates (2) have reported a study of the hemodynamic response to exercise of a group of ten men whose ages ranged from 65 to 83 , with a mean age of 70.7 years. The mean cardiac output of nine of these subjects during supine leg exercise on a bicycle ergometer at a level of severity sufficient to increase the mean oxygen consumption of the group to $498 \mathrm{ml}$ per minute per $\mathrm{m}^{2}$ was $7.18 \mathrm{~L}$ per minute per $\mathrm{m}^{2}$. A comparison of these values with the regression lines of the relationship between oxygen uptake and cardiac output is seen in Figure 1, which indicates only a slight difference for this relationship between our findings in the older normal subjects with a mean age of 47.4 years (Figure $1, \mathrm{~B})$. The coordinate points for the aged subjects of the Swedish study would fall slightly

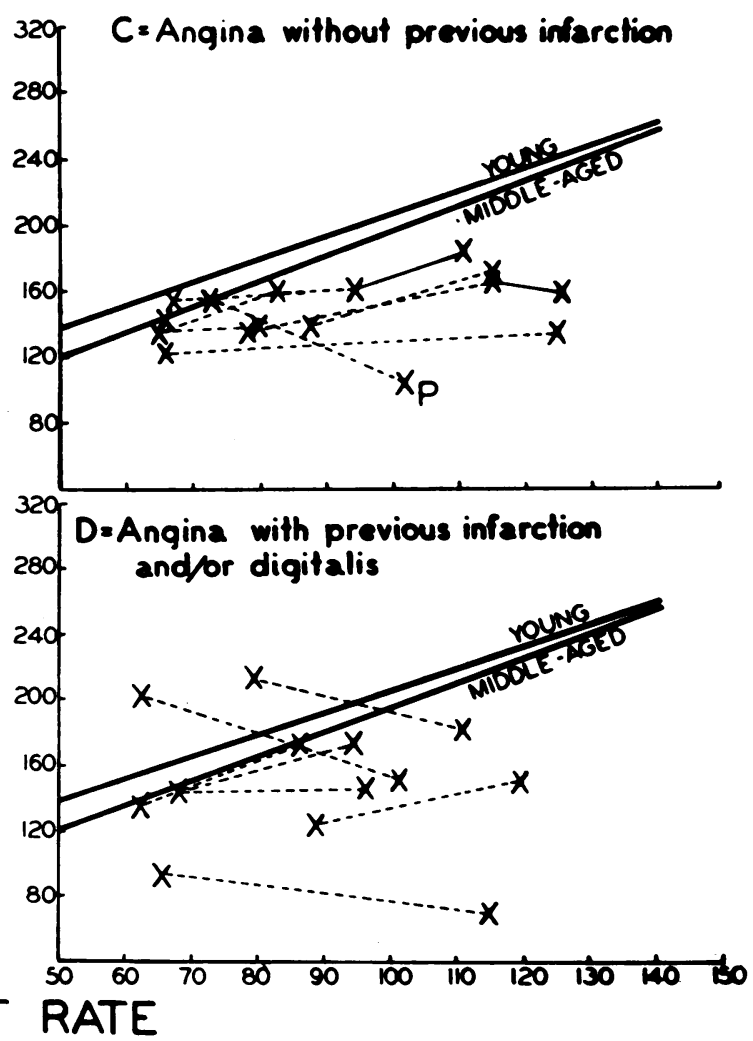

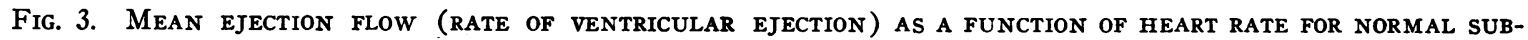
JECTS AND ANGiNa PECtoris patients. The heavy lines are the mean regression lines for young and middle-aged normal subjects. 
below the regression lines for the normal groups of the present study.

These observations appear consistent with the fact that the resting cardiac output per unit surface area has been shown to decline by Brandfonbrener, Landowne, and Shock (13) at the rate of approximately $24.4 \mathrm{ml}$ per year. Moreover, as shown by Shock, Yiengst, and Watkin (14), a directionally similar, although less marked, decrease in body water and basal metabolic rate also occurs with age. These observations suggest that if indexes more closely related to lean muscle mass than the body surface area were used, the magnitude of the apparent decline in resting cardiac output would be reduced. It is also true that the mean value of the resting cardiac index of our older normal subjects was lower than that of our younger subjects by almost exactly the amount anticipated by the studies of Brandfonbrener and colleagues (13) : approximately $300 \mathrm{ml}$ per minute per $\mathrm{m}^{2}$. During exercise, although not statistically significant with the number of subjects in the present study, the regression line for the older subjects was depressed by approximately the same amount, although the slopes of the regression were almost identical. Thus, our findings are seemingly consonant with those reported by others and add additional evidence that the cardiac output response to effort is affected surprisingly little by age alone.

It is important to realize that the levels of exercise used in the present study-in both groups of normal subjects and in patients with angina pectoris-were submaximal, as evidenced by the fact that none of the patients had heart rates over 130 beats per minute. The finding that there was no significant difference in cardiac output between young and older normal subjects at these submaximal levels of exercise in no way implies that their maximal oxygen consumptions and cardiac outputs would be similar. Indeed, it has been shown by Mitchell, Sproule, and Chapman (15) and by Robinson (16) that the maximal oxygen consumption and maximal cardiac output do decrease with age.

Other hemodynamic variables seem to be affected to a similar extent by age. The stroke volume at rest was only slightly less in the older normal subjects than in the younger group, although not sufficiently so in this study to be significant. During exercise, all the normal subjects of both age groups showed an increase in stroke volume as compared to rest, so that a significant $(p<0.02)$ correlation between the stroke volume and oxygen consumption was found $(r=0.42$ in the older subjects; $r=0.48$ in the younger group). The findings relative to stroke volume are in keeping with those found by Taylor, Reeves, and Donald (17) for multiple levels of exercise in the same subjects. After a period of uncertainty it now seems clear that even in the supine position in untrained subjects, the transition from rest to moderate leg exercise is marked by an increase in stroke volume. Subsequently, more severe exercise may result in a slight further increase, in no change, or in a decrease. It is also clear that the changes in stroke volume are considerably less than those of the heart rate. They are, however, of sufficient magnitude to constitute a very important part of the increased cardiac output in response to exercise. The aged subjects of Granath and co-workers (2) increased their stroke volume from a mean of $43.4 \mathrm{ml}$ per $\mathrm{m}^{2}$ to $51.3 \mathrm{ml}$ per $\mathrm{m}^{2}$ at the first level of exercise, and to $54 \mathrm{ml}$ at the second. Our observations on middle-aged men are strikingly similar, although our mean values are slightly higher. Age seemingly does not in itself change the pattern of the stroke volume response to effort. As can be inferred from the preceding comments, the heart rate at any given work level was not greatly different in the two age groups of the normal subjects of the present study. Again, the aged Swedish subjects were not significantly different in this regard from their younger group and are almost identical with our middle-aged subjects (Figure 2, B).

The duration of ejection at any given heart rate was slightly, but not significantly, greater in the older subjects than in our younger ones. Since the stroke volume was not different, the mean ejection flow (stroke index/duration ejection) was slightly less in our older subjects.

There appears then to be a very slight but steady decrease in cardiac output, stroke volume, and mean ejection flow with aging, both at rest and during moderate, supine leg exercise. The arterial pressure, peripheral vascular resistance, and useful left ventricular work tend to increase in relation to age. These changes are insufficient 
to explain the hemodynamic alterations noted in our subjects with angina pectoris. Both quantitative and qualitative differences of marked degree have been demonstrated. It would seem highly inaccurate to regard coronary heart disease and aging as being physiologically synonymous.

Hemodynamic consequences of angina pectoris. Almost certainly there exists a continuous spectrum of severity of coronary heart disease. It is impossible, therefore, to generalize upon the characteristics of this disease in a quantitatively undifferentiated group of patients with this disorder. One of the purposes of our investigation was to study certain hemodynamic responses of a group of middle-aged male patients with undoubted angina pectoris who were not in overt heart failure and who were capable of at least moderately severe exercise without chest pain. These were compared with clinically normal persons of the same age. The conclusions that are reached in this study obviously apply only to those patients with angina that can be so defined. The abnormal hemodynamic findings that characterize these individuals with angina pectoris were apparent only with exercise. The findings at rest were usually indistinguishable from those of normal subjects. It is important to realize that the levels of work performed by the patients with angina were below those that would induce pain. The most notable of these changes relative to the external work performed and oxygen utilized include 1) a reduced cardiac output, 2) a decreased stroke volume, and 3 ) a reduction of the mean rate of ventricular ejection of any given heart rate.

A failure to increase the mean ejection flow (mean systolic ejection rate) with exercise was found by Messer and co-workers (7) in patients with angina pectoris who did not have apparent congestive failure. Levine and associates (3) also noted an inability to increase the mean systolic ejection rate in patients with aortic stenosis without ventricular failure, as well as in patients with congestive failure. These authors suggested that this failure to increase the mean ejection flow was due to systolic hypertension in the former and to "excessive rise in muscle wall tension by virtue of dilatation" in the latter.

The rate of ejection is determined by the velocity of shortening of the cardiac muscle and the size of the heart (18). Thus, if the heart is en- larged, a given shortening of the myocardium will result in an increased stroke volume, and if the velocity of shortening is unchanged, the rate of ejection will be increased. The velocity of shortening of a given muscle, either skeletal or cardiac, is determined by 1 ) the load resisting shortening, 2) the stretch or length of the muscle, and 3) the physiologic fitness or contractility of the muscle. The load and rate of shortening vary inversely according to the force-velocity relationship of Hill (19), shown recently in cardiac muscle by Abbott and Mommaerts (20) and Sonnenblick and Downing (21). The load resisting shortening of the myocardial fibers in the heart at any instant is equal to the tension existing in those fibers at the same time. This tension also varies with the size of the ventricular cavity as has recently been demonstrated experimentally by Hefner, Sheffield, Cobbs, and Klip (22). In applying these known facts to the findings of the present experiments, we conclude that three factors may have contributed to the reduced rate of ejection that characterized the patients with angina pectoris. Either 1) the contractility of the myocardium was reduced, or 2) the tension (i.e., load resisting shortening) was increased disproportionately, or 3) the ventricular cavity was smaller. In the present study the pressure during ejection was slightly greater, and the cavity size of the left ventricle was quite possibly greater in the subjects with angina than the middle-aged normal group. The increased cavity size would, as shown above, result in an increased rate of ejection relative to the velocity of shortening. In addition, the increased fiber length resulting from the increased size would also tend to increase the velocity of shortening at any given load greater than zero if the contractility were unchanged (21). On empiric grounds it would seem unlikely that the increased ejection pressure in the patients with angina would be important in this regard, since Taylor and colleagues (17) have found no significant diminution in the rate of ejection in markedly hypertensive compensated subjects. Seemingly, therefore, the reduced rate of ejection observed in the patients with angina pectoris is the result of a distinct diminution in myocardial contractility, likely the result of inadequate coronary blood flow. 


\section{Summary}

The hemodynamic responses to exercise in two groups of middle-aged men have been compared to each other and to those of young normal volunteers. One group, with a mean age of 47.4 years, was clinically normal; the other, with a mean age of 48.7 years, had classic angina pectoris but was not in congestive heart failure. There was no statistically significant reduction of the cardiac output, stroke volume, or mean rate of ejection in the middle-aged normal subjects as compared to the younger group. A wellmarked reduction in each of these variables at comparable levels of exercise was found in the subjects with angina pectoris as compared to either of the two normal groups. The hemodynamic consequences of angina pectoris are therefore considerably different from those due to aging.

\section{Acknowledgments}

We wish to express our appreciation to Drs. John Burrett and Robert Yoe for their clinical evaluation of the patients. We are indebted to Dr. Sam Englehardt, Jr., for participation in a number of the studies, and to Miss M. M. Tims and Miss Phyllis Hutchinson for valued editorial assistance.

\section{References}

1. Foster, G. L., and T. J. Reeves. Cardiovascular response to exercise in patients with angina pectoris (abstract). Circulation 1961, 24, 934.

2. Granath, A., B. Jonsson, and T. Strandell. Studies on the central circulation at rest and during exercise in the supine and sitting body position in old men. Acta med. scand. 1961, 169, 125.

3. Levine, H. J., W. A. Neill, R. J. Wagman, N. Krasnow, and R. Gorlin. The effect of exercise on mean left ventricular ejection rate in man. J. clin. Invest. 1962, 41, 1050.

4. Weissler, A. M., R. G. Peeler, and W. H. Roehll, Jr. Relationship between left ventricular ejection time, stroke volume, and heart rate in normal individuals and patients with cardiovascular disease. Amer. Heart J. 1961, 62, 367.

5. Lewis, B. M., H. E. J. Houssay, F. W. Haynes, and L. Dexter. The dynamics of both right and left ventricles at rest and during exercise in patients with heart failure. Circulat. Res. 1953, 1, 312.

6. Müller, O., and K. Rørvik. Hæmodynamic consequences of coronary heart disease with observations during anginal pain and on the effect of nitroglycerine. Brit. Heart J. 1958, 20, 302.
7. Messer, J. V., H. J. Levine, R. J. Wagman, and R. Gorlin. Effect of exercise on cardiac performance in human subjects with coronary artery disease. Circulation 1963, 28, 404.

8. Bousvaros, G. A., W. H. Palmer, P. Sekelj, and M. McGregor. Comparison of central and peripheral injection sites in the estimation of cardiac output by dye dilution curves. Circulat. Res. 1963, $12,317$.

9. Hamilton, W. F., J. W. Moore, J. M. Kinsman, and R. G. Spurling. Studies on the circulation. IV. Further analysis of the injection method, and of changes in hemodynamics under physiological and pathological conditions. Amer. J. Physiol. 1932, 99, 534.

10. Donald, K. W., J. M. Bishop, G. Cumming, and O. L. Wade. The effects of exercise on the cardiac output and circulatory dynamics of normal subjects. Clin. Sci. 1955, 14, 37.

11. Steel, R. G. D., and J. H. Torrie. Principles and Procedures of Statistics, with Special Reference to the Biological Sciences. New York, McGrawHill, 1960.

12. Holmgren, A., B. Jonsson, and T. Sjöstrand. Circulatory data in normal subjects at rest and during exercise in recumbent position, with special reference to the stroke volume at different work intensities. Acta physiol. scand. 1960, 49, 343.

13. Brandfonbrener, M., M. Landowne, and N. W. Shock. Changes in cardiac output with age. Circulation $1955,12,557$.

14. Shock, N. W., M. J. Yiengst, and D. M. Watkin. Age change in body water and its relationship to basal oxygen consumption in males (abstract). J. Geront. 1953, 8, 388.

15. Mitchell, J. H., B. J. Sproule, and C. B. Chapman. The physiological meaning of the maximal oxygen intake test. J. clin. Invest. 1958, 37, 538.

16. Robinson, S. Experimental studies of physical fitness in relation to age. Arbeitsphysiologie 1938, 10, 251.

17. Taylor, S. H., T. J. Reeves, and K. W. Donald. Hemodynamic response to multiple levels of uninterrupted exercise. To be published.

18. Braunwald, E., S. J. Sarnoff, and W. N. Stainsby. Determinants of duration and mean rate of ventricular ejection. Circulat. Res. 1958, 6, 319.

19. Hill, A. V. The heat of shortening and the dynamic constants of muscle. Proc. roy. Soc. B. 1938, 126, 136.

20. Abbott, B. C., and W. F. H. M. Mommaerts. A study of inotropic mechanisms in the papillary muscle preparation. J. gen. Physiol. 1959, 42, 533.

21. Sonnenblick, E. H., and S. E. Downing. Afterload as a primary determinant of ventricular performance. Amer. J. Physiol. 1963, 204, 604.

22. Hefner, L. L., L. T. Sheffield, G. C. Cobbs, and W. Klip. Relation between mural force and pressure in the left ventricle of the dog. Circulat. Res. 1962, 11, 654. 